\title{
Educação do Campo e o programa Projovem Campo em Planaltina/DF
}

\author{
Marina Morenna Alves de Figueiredo ${ }^{1}$, Maria da Conceição da Silva Freitas ${ }^{2}$ \\ ${ }^{1}$ Universidade de Brasília - UnB. Centro de Educação. Instituto de Pesquisa Econômica Aplicada. Setor Asa Sul, \\ Brasília - DF. Brasil. Brasil. morennafigueiredo@ gmail.com. ${ }^{2}$ Universidade de Brasília - UnB.
}

RESUMO. A Política Nacional de Juventude (PNJ) demonstra o reconhecimento do Governo sobre a necessidade de políticas sociais específicas para este segmento. Dentre as diversas políticas para a juventude, a presente pesquisa buscou retratar o Programa Projovem Campo, na área de educação, destinado a promover a conclusão do ensino fundamental dos jovens, de 18 a 29 anos, que já deveriam ter concluído tal etapa. Para elucidar a importância desta política pública foi realizado um estudo de caso no Centro de Ensino Fundamental Pipiripau II, na zona rural de Planaltina/DF e foram feitas entrevistas com os gestores, coordenadores, professores e estudantes do Programa Projovem Campo nesta unidade de ensino. Os resultados do trabalho de campo indicaram dificuldades na implementação e execução do programa. Entre as principais dificuldades destacam-se o não cumprimento de ações estabelecidas no desenho da política, como a refeição oferecida que não era jantar, as rotas dos ônibus e o impedimento de transportar crianças, a falta de um espaço específico e de materiais para a sala de acolhimento, além do não pagamento da bolsa auxílio para os estudantes.

Palavras-chave: Juventude, Educação do Campo, Programa Projovem Campo. 


\title{
Rural Education and the Projovem Countryside Program in Planaltina/DF
}

\begin{abstract}
The National Policy of Youth demonstrates the recognition of the government about the necessity of specific social politics addressed to this segment. Among several policies for youth, this research seeks to reveal the Program Projovem Campo, at the area of education, to promote the conclusion of elementary school for those between 18 and 29 years old that should had conclude such degree. To elucidate the importance of this policy, it was conducted a study case at Centro de Ensino Fundamental Pipiripau II, in the rural area of Planaltina/DF, and interviews with managers, coordinators, teachers and students of the Program of this unity. The results of the fieldwork indicated difficulties on the implementation and execution of the program. Among the main difficulties are highlighted the non-compliance of established actions at the design of the policy, such as the meal provided, the bus routes and the impairment of the transportation of kids, the lack of specific space and materials for the hosting room for children, besides the non-payment of stipend for the students.
\end{abstract}

Keywords: Youth, Rural Education, Program Projovem Campo. 


\section{Educación Rural y Programa Projovem del Campo en Planaltina/DF}

RESUMEN. La Política Nacional de la Juventud demuestra el reconocimiento del Gobierno sobre la necesidad de políticas sociales específicas para este segmento. Entre las diversas políticas para la juventud, esta investigación trató de presentar el programa de campo Projovem, en la educación, la promoción de la finalización de la educación primaria de los jóvenes, de 18 a 29 años, que ya debería haber completado este paso. Para dilucidar la importancia de esta política pública se llevó a cabo un estudio de caso en el Centro de Educación Primaria Pipiripau II, en la zona rural Planaltina/DF y se llevaron a cabo entrevistas con los gerentes, ingenieros, profesores y estudiantes del Programa de Campo Projovem esta unidad didáctica. Los resultados del trabajo de campo indican dificultades en la implementación y ejecución del programa. Entre las principales dificultades incluyen la falta de cumplimiento de las medidas establecidas en el diseño de políticas, como la harina de ofrecer pero que no era la cena, las líneas de autobuses y el impedimento para el transporte de los niños, la falta de un espacio y materiales específicos para la sala acoger, además de la falta de pago de las becas para estudiantes.

Palabras clave: Juventud, Educación Rural, Programa Projovem del Campo. 


\section{Introdução}

O Estado brasileiro reconhece suas limitações, em suas diversas instâncias, de atender a demanda da população do campo quanto à escolarização. A organização curricular, que muitas vezes, desconsidera a realidade das pessoas do campo e, a pouca qualificação e remuneração, em geral, dos professores nas áreas rurais do país, entre outros fatores, têm contribuído de sobremaneira para a baixa escolarização no campo.

No intuito de reduzir esta lacuna, em 2005, foi lançado o Programa Nacional de Educação de Jovens e Adultos para Agricultores/as Familiares integrada com Qualificação Social e Profissional, denominado Saberes da Terra. Programa este que dialoga com a diversidade dos povos do campo e que inclui alternância dos estudos e dos períodos produtivos em conformidade com as Diretrizes Operacionais de Educação Básica nas Escolas do Campo (MEC, 2009).

Este programa do Plano Nacional de Educação (PNE) foi direcionado para atender as especificidades da juventude quanto a sua formação educacional em decorrência da implementação da Política Nacional de Juventude (PNJ) que demonstra o reconhecimento do Governo da necessidade de políticas específicas para este segmento da população. Políticas estas, de caráter transversal, que perpassam as demais políticas sociais. Entre tais políticas, destaca-se o Programa Projovem que oferece educação básica aliada à formação profissional aos jovens que não concluíram o ensino fundamental.

O programa Projovem Integrado inclui o Projovem Adolescente, o Projovem Trabalhador, o Projovem Urbano e o Projovem Campo. Os dois últimos programas têm como finalidade oferecer formação integral aos jovens de 18 a 29 anos, que não completaram o ensino fundamental, associando a formação básica para elevação da escolaridade à Qualificação Profissional Inicial (MEC, 2013).

No processo de integração do Programa Projovem foi resguardada a autonomia político-pedagógica das experiências de cada programa integrado e o Programa Saberes da Terra passou a denominar-se Projovem Campo - Saberes da Terra, destinado a garantir ensino fundamental a jovens agricultores, como política de educação, na modalidade de Educação de Jovens e Adultos (EJA) integrada à qualificação social e profissional (MEC, 2009).

Esse Programa se destaca por ter uma série de ações para minimizar a evasão escolar, dando parte do suporte 
necessário para o estudo e que esses jovens não tiveram acesso, como transporte público e gratuito que passa nas comunidades para levá-los à escola, sala de acolhimento para as crianças que são filhas das estudantes do programa, refeição, material escolar e uniforme gratuitos e uma bolsa auxílio para os estudantes. Contudo, veremos que a política nem sempre é implementada e executada conforme previsto na sua formulação.

Neste sentido, este trabalho analisa o perfil dos estudantes atendidos no Programa Projovem Campo, no intuito de levantar se esta política tem beneficiado os jovens do campo ao acesso e permanência na educação e busca também retratar o que pensam os jovens, além dos professores e coordenadores, sobre a execução deste programa no Centro de Ensino Fundamental (CEF) Pipiripau II de Planaltina/DF.

\section{Metodologia}

A opção por um método, bem como por distintos procedimentos metodológicos que foram utilizados na pesquisa, demonstra as afinidades quanto às concepções de mundo e experiências de vida das pesquisadoras. Afinal, o método científico está intrinsecamente relacionado com a visão de mundo do pesquisador.
Assim, nesta pesquisa buscou-se uma análise comprometida com a perspectiva não eurocêntrica ou afrocentrada na construção da ciência, destacando a população negra (afrodescendente) nos processos sociais.

Isto posto, primeiramente foi realizado um levantamento bibliográfico a fim de averiguar a produção sobre a temática da juventude e as políticas públicas destinadas a este segmento. Concomitantemente, considera-se na revisão da literatura a transversalidade de gênero e raça nas políticas públicas relacionando-os com as políticas destinadas a Educação do Campo.

Em seguida, foi feito um levantamento das instituições do Distrito Federal (DF) que realizam o Programa Projovem Campo no Distrito Federal. Notadamente, havia uma única escola executora do Programa, no ano de 2016, no DF, indicando que a execução deste programa nesta Unidade da Federação era incipiente. $\mathrm{Na}$ época, a única escola executora do Programa Projovem Campo era o Centro de Ensino Fundamental Pipiripau II, na zona rural de Planaltina/DF e, portanto, foi à única opção de estudo de caso do Programa Projovem Campo no Distrito Federal.

Definido o local do trabalho de campo, inicialmente foi realizado contato 
com a escola que prontamente aceitou a realização desta pesquisa. Foram realizados trabalhos de campo, ao longo de três meses, à noite, horário de funcionamento do Programa Projovem, no CEF Pipiripau II. Ao longo dos trabalhos de campo, como método de coleta de dados, foram realizadas entrevistas com estudantes, com os coordenadores, professores e com as educadoras sociais voluntárias do Programa Projovem Campo (Tabela 1). Todos os participantes receberam uma Carta de Apresentação da Pesquisa e um Termo de Esclarecimento e Liberdade de Recusa, devidamente assinado pelos entrevistados.

Tabela 1 - Número de entrevistados no CEF Pipiripau II em 2016.

\begin{tabular}{cc}
\hline ENTREVISTADOS & NÚMERO \\
\hline Diretores da escola & 1 \\
Coordenadores da escola e do programa & 2 \\
Professores do programa na escola & 5 \\
Educadoras sociais do programa & 2 \\
Estudantes & 5 \\
\hline Total de entrevistas & 15 \\
\hline Fonte: Dados próprios da presente pesquisa. \\
Elaboração: Figueiredo, 2016.
\end{tabular}

Outro método de coleta de dados foi à elaboração e aplicação de um questionário aos alunos matriculados no Programa Projovem Campo desta unidade executora a fim de traçar o perfil destes jovens e sua percepção sobre o Programa. A partir do levantamento do número de matriculados (120) no programa nesta escola, buscou-se aplicar o questionário aos frequentes (60), contudo, foram respondidos 39 questionários. A escolha das estudantes entrevistadas foi feita a partir da tabulação dos questionários considerando a auto declaração de sexo e raça/cor. As entrevistas foram gravadas e, em seguida, transcritas, tabuladas e analisadas.

\section{Resultados e discussões}

A área rural compõe a maior parte da região administrativa de Planaltina/DF e é subdividida em quatro, a saber: Taquara, Tabatinga, Rio Preto e Pipiripau que tem seu acesso por meio da BR 020, e é onde se localiza a unidade promotora do Programa Projovem Campo no Distrito Federal. A escola foi fundada em 1969 e funcionava, inicialmente, em uma área 
cedida por um morador da região de Pipiripau. Somente em 1980 foi inaugurado o prédio escolar construído pela comunidade. Segundo Portilho (2006), a escola foi uma reivindicação do movimento de moradores do Pipiripau criado na década de 1960 para emancipação destes do Núcleo Rural de Taquara. No ano de 1997 a escola inaugura a biblioteca, aumenta o número de atendimentos e é denominada Centro de Ensino Fundamental (CEF) Pipiripau II.

Atualmente, a maior parte dos docentes e funcionários reside nas cidades do Estado de Goiás devido à proximidade de Formosa/GO e de Planaltina/GO ao Núcleo Rural de Pipiripau. O Centro de Ensino Pipiripau II de Planaltina/DF funciona durante $\mathrm{o}$ dia atendendo as crianças da comunidade com alunos matriculados em regime integral e parcial. A escola conta com biblioteca, dois pavilhões de salas de aula, e refeitório.

Recentemente, no ano de 2015, com a execução do Programa Projovem Campo a escola passou a funcionar à noite atendendo jovens estudantes de Pipiripau e também provenientes de outras sete comunidades. Estes jovens têm transporte de segunda à quinta-feira (período das aulas) às 18 horas de sua comunidade até a escola. As atividades do Programa iniciamse às 19 horas com um jantar para os alunos, seguida às 19 h20min das aulas que se encerram às 22 horas. Os estudantes também contam com um período no calendário letivo em que as aulas são realizadas aos sábados no campo, atendendo a conformidade de alternância, no qual eles percorrem as comunidades e visitam locais de produção.

A diretriz das escolas do campo foi fruto de décadas de luta dos movimentos sociais na pauta da educação no campo. A partir desta, as escolas de Educação do Campo deverão promover as adaptações necessárias a sua adequação às peculiaridades da vida rural e de cada região, especialmente assegurando: I conteúdos curriculares e metodologias apropriadas às reais necessidades $\mathrm{e}$ interesses dos alunos da zona rural; II organização escolar própria incluindo a adequação do calendário escolar às fases do ciclo agrícola e às condições climáticas; III - adequação ao trabalho na zona rural (MEC, 2009).

A partir desta diretriz, definiu-se a fundamentação, os objetivos e as metas do Programa Projovem Campo. No que tange as bases conceituais de referência $o$ programa versa entre diversos pilares, a saber: Educação do Campo, educação de jovens e adultos, desenvolvimento sustentável, trabalho e economia solidária e qualificação social e profissional (MEC, 
2009).

Quanto aos objetivos o Ministério da Educação definiu que o Programa visa:

Contribuir para a formação integral do jovem do campo, potencializando a sua ação no desenvolvimento sustentável e solidário de seus núcleos familiares e comunidades, por meio de atividades curriculares e pedagógicas, em conformidade com o que estabelecem as Diretrizes Operacionais para Educação Básica nas Escolas do Campo - Resolução CNE/CEB $n^{\circ} 1$ de 03 de abril de 2002 (MEC, 2009).

Já as metas fazem parte do Plano Nacional de Educação, do Plano Nacional de Políticas para as Mulheres e do Plano Nacional de Juventude. Todos estes planos somam esforços e indicam ações para elevar a escolarização de jovens mulheres do campo aliados a qualificação social e profissional.

Segundo o MEC, a elevação de escolaridade associada à qualificação social e profissional no Programa Projovem Campo se propõe a possibilitar diversas aprendizagens e dentre estas destacam-se: reconhecer e valorizar a linguagem de seu grupo social como instrumento adequado e eficiente na comunicação; reconhecer a relação entre conhecimento organizado pelas ciências e o conhecimento dos agricultores familiares construídos, acumulados, organizados, repassados e aperfeiçoados ao longo de várias gerações; formular questões, elaborar diagnósticos e propor soluções para problemas reais enfrentados na Agricultura Familiar; elaborar e desenvolver, projetos de melhorias nas condições das unidades familiares; analisar criticamente o papel, a importância da organização e da representação política da agricultura familiar num processo de desenvolvimento (MEC, 2009).

Para tanto, é importante que os conteúdos curriculares sejam adaptados à realidade dos moradores do campo. Isto torna-se possível, pois a Educação do Campo assegura, como princípio, a organização adequada dos tempos e espaços formativos à realidade do campo e assegura também a flexibilização da organização do calendário escolar sob a forma da alternância. No Programa Projovem Campo - Saberes da Terra a alternância acontece por meio de dois tempos-espaços específicos: Tempo-escola e Tempo-comunidade.

Atendendo a essa especificidade, o coletivo de professores do Projovem Campo no CEF Pipiripau II organizou o calendário escolar de modo que os estudantes tenham no Tempo-escola dois meses de aulas no espaço da escola, seguidos do Tempo-comunidade de duas semanas de duração no qual as aulas são ministradas aos sábados nas comunidades 
atendidas seguindo o Tempo-itinerante (criado por esse coletivo de professores) para que cada aula de prática no campo seja em uma comunidade diferente, mantendo-se a alternância entre Tempoescola e Tempo-comunidade. Sobre esta prática uma professora acrescenta:

O Projovem Itinerante foi uma experiência muito boa, tanto para eles, a gente viu isso no resultado, na escrita da síntese o quão foi enriquecedor para eles, (tanto para nós que) inclusive ajudou a nortear a nossa própria prática enquanto educadores (Entrevista realizada com a Professora 1).

Como citado, as entrevistas com os professores apontam que o Tempocomunidade/Tempo-itinerante é um momento muito rico no qual os estudantes têm a percepção de que estão aprendendo, conseguem ver de fato aplicabilidade na teoria ensinada no Tempo-escola que é organizado com base na transdisciplinaridade da Agricultura Familiar e da Agroecologia como temas estruturantes do currículo. Sobre esta proposta pedagógica, um professor acrescenta:

Eu achei a proposta extremamente interessante porque o que eles vêm colocando como objetivos e a pedagogia que está sendo utilizada me deixaram encantado, mas te confesso que não tinha nenhuma experiência anterior em sala de aula com um programa dessa natureza então para mim também é uma novidade e eu me sinto muito a vontade porque ... nesse programa nós temos uma liberdade danada para fazer as coisas e a transdisciplinaridade, por exemplo, a gente coloca a agroecologia como carro-chefe dos livros didáticos, mas que isso fica entremeado o tempo inteiro por matemática, por português, por história, geografia, tanto que eu tenho uma certa dificuldade de, às vezes, talvez admitir alguns limites por que eu estou falando de $2^{\mathrm{a}}$ Guerra Mundial e o cara diz como é que esse cara está falando de $2^{\mathrm{a}}$ Guerra Mundial se a gente está falando de agroecologia e tem tudo a ver né? Às vezes eu estou dando aula de matemática de regra de três porque eu estou falando de uma questão de produção e tem tudo a ver, mas por outro lado os alunos estão tão acostumados, tão viciados nessa escola 'bancária' digamos assim como Paulo Freire dizia que eles não conseguem entender que aquilo ali é aula, só que a gente está conversando e eles precisam que eu vá para o quadro passar dever e eles querem copiar e achar que estão na aula (Entrevista realizada com o Professor 2).

Essa fala evidencia que projetos diferentes, modernos, ousados ou com arranjos que vão contra a lógica do sistema educacional ainda são difíceis de concretizar, quer seja por dificuldade dos professores em integrar e transdisciplinarisar os conteúdos, quer seja por dificuldade dos estudantes que estão habituados ao modelo tradicional de educação. Importante destacar também que nas entrevistas com as estudantes a maioria citou que o aprendizado é mais fácil no 
Projovem Campo - Saberes da Terra porque os temas abordados são sobre agricultura, plantações, adubação, enfim, sobre como cultivar a terra, temas estes relacionados à realidade destas jovens no dia a dia no campo. E, quem são estes jovens estudantes? Qual é a realidade vivenciada quanto a sua escolarização?

Os dados dos trabalhos de campo revelam, primeiramente, que nem todos os estudantes atendidos pelo Programa Projovem Campo no CEF Pipiripau II são jovens, ou seja, não estão na faixa etária de 18 a 29 anos. A escola recebe todas as pessoas que querem estudar e tem matriculado não só jovens, mas adultos e idosos. A escola aguardava a oferta também de uma turma de EJA para acolher os adultos e idosos por meio do Programa DF Alfabetizado. Esse programa foi efetivado em maio de 2016, mas a escola tem recebido estes estudantes fora da faixa etária da juventude utilizando a mesma infraestrutura (transporte, alimentação, acolhimento) do Programa Projovem Campo, com exceção de uma professora que foi enviada para a turma de alfabetização dos adultos e idosos.

Outra questão fundamental é o nível de escolarização destes estudantes. O Programa Projovem estabelece em seus critérios que o jovem seja alfabetizado para que possa concluir o ensino fundamental, contudo há estudantes analfabetos. Deste modo, a coordenação do programa organizou as turmas de acordo com o nível de escolarização para atender também os estudantes analfabetos que posteriormente foram remanejados para a turma do DF Alfabetizado.

Inicialmente, em agosto de 2015, havia 120 estudantes matriculados divididos em cinco turmas (A, B, C, D e E). No começo de 2016, por causa do número de evasões, as turmas foram reagrupadas em Flor do Pequi (A), Ipê Amarelo (B) e Girassol (C). Segundo estimativa do coordenador, havia, em média, 60 alunos frequentando o curso. Ao longo do trabalho de campo, foram aplicados 39 questionários aos estudantes presentes dos quais apenas 26 estavam na faixa etária da juventude e foram considerados para traçar o perfil dos jovens atendidos pelo programa. Entre estes destaca-se que a maioria (54\%) dos jovens estudantes era de homens, conforme Tabela 2. 
Tabela 2: Jovens agrupados de acordo com o sexo em 2016.

\begin{tabular}{cc}
\hline Mulheres & 12 \\
\hline Homens & 14 \\
\hline Total & 26
\end{tabular}

Fonte: Dados próprios da presente pesquisa. Elaboração: Figueiredo, 2016.

A partir do total de jovens foram traçadas outras características como a auto declaração de cor ou raça. Para tanto, foi considerada a definição da categoria de negros, que é a somatória dos declarados pardos e pretos indicando que a maioria dos jovens/as (80\%) desta unidade de ensino são negros, conforme Tabela 3:

Tabela 3: Jovens agrupados de acordo com a cor em 2016.

\begin{tabular}{cc}
\hline Mulheres negras & 10 \\
\hline Homens negros & 11 \\
\hline Total de negros & 21 \\
\hline $\begin{array}{c}\text { Fonte: Dados próprios da presente pesquisa. } \\
\text { Elaboração: Figueiredo, }\end{array}$ & 2016.
\end{tabular}

Apesar de, no campo educacional, a discrepância entre homens e mulheres ter diminuído nas últimas décadas, a desigualdade racial se mantém fazendo com que os negros tenham oportunidades limitadas para concluírem a educação básica. No que se refere à escolarização, as desigualdades entre brancos e negros estão relacionadas a múltiplos fatores, dentre estes, renda familiar, acesso a bens públicos e racismo institucional. As consequências para a população negra se traduzem, entre outros fatores, em menor frequência escolar e taxas de escolarização líquida de negros inferiores às de brancos nos ensinos médio e superior (IPEA, 2014).
O fato de a maioria dos jovens estudantes, nesta unidade de ensino, serem negros corrobora a tese acima de que a população negra tem maior dificuldade de acesso e permanência na escola, evidenciando a importância das políticas de Educação de Jovens e Adultos para a população negra.

Quanto ao domicílio, do total de 26 jovens, a maioria destes mora em casa própria, o que representa $62 \%$ e $23 \%$ em casa cedida, provavelmente por algum familiar, e outros $8 \%$ moram em casa alugada. Quanto à situação do domicilio em relação à localização a grande maioria (23 jovens o que representa $88 \%$ ) têm sua casa situada na zona rural e, o restante (3 
jovens) têm sua casa na zona urbana

conforme o gráfico 1, abaixo:

Figura 1: Situação de domicilio dos jovens em 2016.

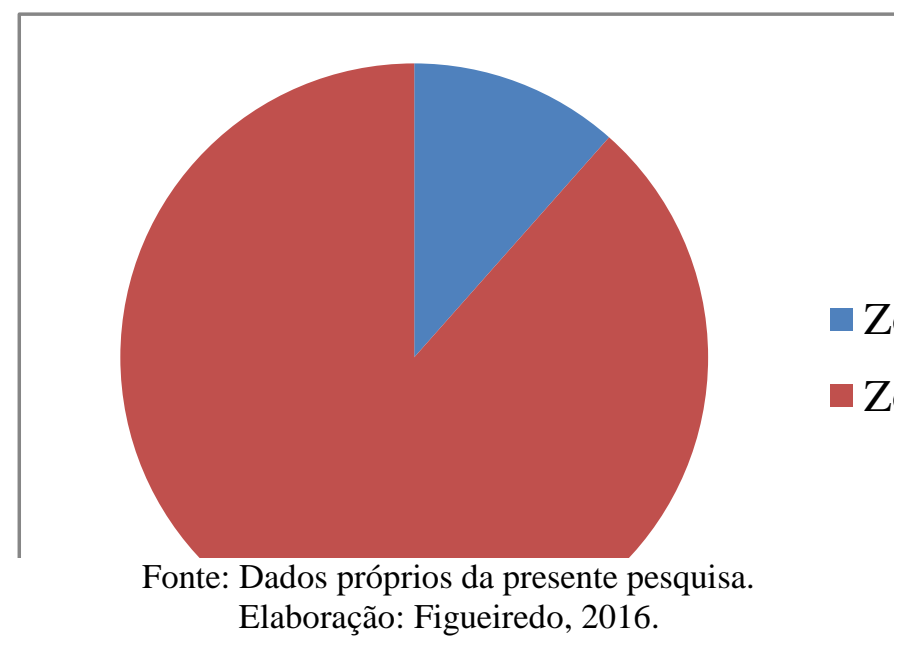

Quanto à situação escolar destes pois a maioria já reprovou de série pelo jovens, percebe-se que dentre os vários menos uma vez (Tabela 4), e entre estes motivos que fizeram com que estes alguns reprovaram de série três vezes ou abandonassem a escola, destacam-se as mais.

dificuldades no percurso formativo regular,

Tabela 4: Percurso formativo dos jovens em 2016.

\begin{tabular}{cc}
\hline Reprovou de série & 23 \\
\hline Nunca reprovou & 3 \\
\hline Fonte: Dados próprios da presente pesquisa. \\
\multicolumn{2}{c}{ Elaboração: Figueiredo, 2016. }
\end{tabular}

Os dados do questionário mostram também que a maioria dos jovens, cerca de $60 \%$, afirmaram que trabalhar enquanto estudava prejudicou a sua formação. Essa afirmação pode indicar que parte das dificuldades enfrentadas por estes jovens advenham da necessidade de trabalhar e ter que conciliar o trabalho com estudos e vida familiar, uma árdua tarefa.

Com relação ao trabalho destes jovens, a maioria (quase 50\%) afirmou trabalhar na agricultura, seguido do trabalho na construção civil, de trabalhos domésticos para terceiros e trabalhos informais em casa, além do trabalho do lar. O trabalho na indústria foi o menos citado, conforme se verifica no gráfico 2 abaixo: 
Figura 2: Distribuição dos jovens segundo atividade laboral dos estudantes em 2016.

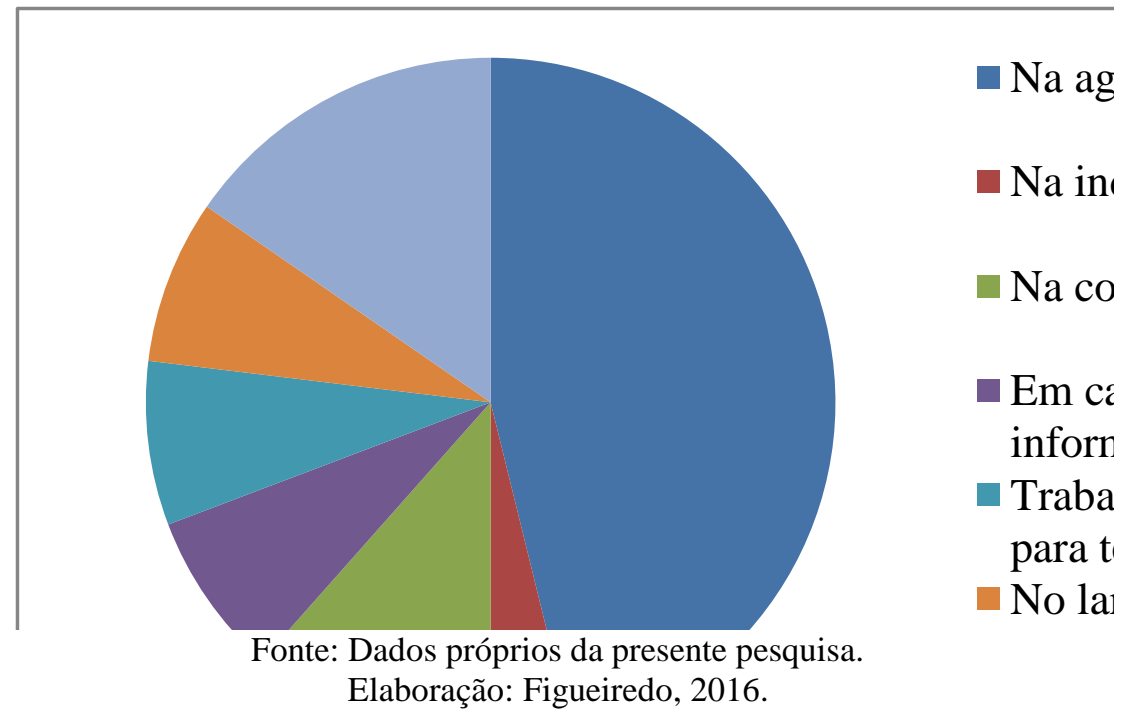

Quando inqueridos sobre qual o melhor, conforme a Tabela 5. Também foi principal motivo que os fizeram voltar a apontada, por estes jovens, a vontade de estudar, diversas razões foram apontadas, a adquirir novos conhecimentos e a maioria delas vinculadas a conseguir um disponibilidade do curso como emprego ou conseguir outro emprego motivadores para o retorno aos estudos.

Tabela 5: Principal motivo dos jovens do Projovem para voltar a estudar em 2016.

\begin{tabular}{cc} 
Conseguir emprego & 4 \\
\hline Conseguir um emprego melhor & 8 \\
\hline Progredir no emprego atual & 2 \\
\hline Adquirir mais conhecimento & 5 \\
\hline Disponibilidade do curso & 2 \\
\hline Outro & 5 \\
\hline Fonte: Dados próprios da presente pesquisa. \\
Elaboração: Figueiredo, 2016.
\end{tabular}

Mesmo diante do retorno destes jovens a escola, o índice de evasão é altíssimo (maior que 50\%), indicando que os jovens estão tendo dificuldade em se manter no curso. Os principais motivos, citados nas entrevistas pelos professores, que levam ao abandono dos estudos são: o não pagamento da bolsa auxílio do programa aos alunos; o não cumprimento da alimentação prometida (jantar) que no ano de 2016 foi resolvido; a falta da sala de acolhimento que fizeram com que muitas mães desistissem do programa; a falta de material escolar tanto para alunos como 
para os professores; a questão do transporte escolar que passa cedo nas comunidades e alguns trabalhadores não chegam a tempo e o impedimento de transportar crianças nos ônibus, questão esta que foi resolvida.

Também ocorreu a falta dos recursos humanos necessários, como um representante da escola para o noturno, no caso um coordenador, os monitores para o acolhimento das crianças, o pessoal para limpeza e para a preparação da merenda escolar. A escola resolveu parcialmente a questão, ainda em 2015, remanejando o coordenador e o merendeiro do diurno para o noturno e, em abril de 2016, foram enviadas pelo GDF duas educadoras sociais para o acolhimento das crianças.

Além da falta de recursos humanos, o projeto inicia-se também com dificuldades com relação à falta de infraestrutura, de material de limpeza e de material escolar que não foram licitados, falta dos gêneros alimentícios para a merenda, inicia sem a sala de acolhimento e com dificuldades no transporte dos estudantes por ter rotas extensas e porque a empresa se opôs, num primeiro momento, a transportar as crianças. Importante destacar também a falta dos recursos financeiros para o pagamento dos salários dos professores e da bolsa auxílio aos estudantes, ambos sem receber até julho de
2016. Segundo os coordenadores:

\begin{abstract}
A gente inicia o Projovem em uma escola que não tem minimamente a estrutura adequada, mas era o que nós tínhamos ... e acontecem vários problemas de questão de infraestrutura mesmo, de questão pedagógica e administrativa do próprio programa em si que se perpetua à longo prazo até os dias de hoje (Entrevista realizada com o Coordenador 1).
\end{abstract}

Uma preocupação que a escola tem (no momento) é o pagamento dos professores e a bolsa para os educandos, porque foi prometido e até agora é a grande falha da secretaria com o MEC que não está repassando conforme o combinado para os professores e para os educandos (Entrevista realizada com o Coordenador 2).

Destacada as principais dificuldades, denota-se que no processo de implementação podem ocorrer situações imprevistas ou mesmo situações que ocorrem porque a política pública não está sendo executada conforme formulada, por diversos motivos implicando em dificuldades de várias ordens, como as citadas anteriormente. Para Carvalho, Barbosa e Soares (2010, p. 10):

Vários fatores podem interferir na implementação alterando os rumos previstos. São circunstâncias externas ao agente implementador relativas à adequação, suficiência e disponibilidade de tempo e recursos; à característica da política em termos de causa e efeito, aos vínculos e dependências externas; à compreensão e especificação dos 
objetivos e tarefas; à comunicação, coordenação e obediência ... Há ainda os fatores relativos às características do processo de negociação, à natureza do foco da política; às ações e relações entre os implementadores e sua capacidade de adaptação e de aceitar e acomodar imprevistos, às características da equipe, à condições políticas, econômicas e sociais.

Percebe-se, assim, que dificuldades são inerentes ao processo de implementação. Para além desta fase, no ciclo das políticas públicas, implementado o programa a etapa seguinte é avaliação e monitoramento do mesmo. Sem pretender tal função, esta pesquisa buscou indicar a percepção dos atores locais, gestores, coordenadores, professores e estudantes quanto à realização do programa, sua implementação, execução e também como estes avaliavam à experiência vivenciada. Ao perguntar aos professores sobre quais os resultados que poderiam apontar, destacamos:

Muito mais do que aprender a falar ou do que aprender matemática da forma que se optou por ensinar, conteudista e tudo mais, eles chegam aqui com a autoestima baixíssima, a grande maioria, a primeira coisa que eles dizem: 'a professor essa negócio de matemática e português esse negócio eu não sei não', eu digo rapaz você sabe sim, se eu te der um troco errado tu sabe, claro, então você sabe matemática... começo por aí e vou mostrando essa outra visão e eu vejo que a autoestima vai aumentando eles vão começando a se empoderar, dizendo: não pera aí eu não sou um zé ninguém, eu sou gente ... eles sabem que tem um bucado de direitos e eu vou ensiná-los a exercerem, e eles começam ficar mais assim, eles mudam até o jeito de falar e eu estou gostando disso (Entrevista realizada com o Professor $3)$.

Nós temos um coletivo de professores e isso é um avanço, pois para formar um coletivo de professores dentro de uma escola são anos e nós já temos isso, tem esse coletivo que é um grande avanço, nós estamos conseguindo nos aproximar das comunidades dos estudantes isso também está sendo um resultado muito bom (Entrevista realizada com o Professor 4).

Vários outros resultados também foram apontados como o fato da escola finalmente estar aberta para a comunidade à noite, sendo muito boa a aceitação do programa por parte da comunidade; dedicação e empenho do coletivo de professores e dos estudantes, se mantendo mesmo diante das adversidades; o processo de aprendizado itinerante nas comunidades, no qual avaliavam o aprendizado; finalmente, a realização do sonho de dezenas de pessoas que desejavam voltar a estudar e, mais que isso, o incentivo a continuação dos estudos pós-conclusão da educação fundamental, pois muitos sonham em cursar ensino médio e faculdade.

Dado o retorno aos estudos destes jovens, procurou-se saber como eles 
avaliavam o desenvolvimento do programa Projovem Campo. Para tanto, os jovens foram inquiridos sobre a entrega do material e uniforme, sobre a refeição oferecida, sobre a qualidade dos professores e servidores, sobre a bolsa de auxílio financeiro, sobre o transporte oferecido, sobre o acolhimento das crianças e sobre a infraestrutura e a limpeza da escola, dados sistematizados na Tabela 6, abaixo:

Tabela 6: Avaliação dos jovens quanto ao Programa Projovem Campo em 2016.

\begin{tabular}{cccc}
\hline & Ruim & Médio & Bom \\
\hline Entrega de material e uniforme & 6 & 6 & 8 \\
\hline Refeição oferecida & 1 & 9 & 10 \\
\hline Professores e servidores & 0 & 2 & 19 \\
\hline Acolhimento das crianças & 2 & 4 & 15 \\
\hline Bolsa de auxílio financeiro & 19 & 0 & 2 \\
\hline Transporte oferecido & 0 & 6 & 14 \\
\hline Infraestrutura da escola & 1 & 9 & 10 \\
\hline Limpeza da escola & 5 & 2 & 14 \\
\hline Fonte: Dados próprios da presente pesquisa. & \\
Elaboração: Figueiredo, 2016. &
\end{tabular}

Percebe-se na Tabela 6 que a maioria dos estudantes avaliou o programa, de modo geral, como bom. Vale destacar que a entrega do material e do uniforme teve quase o mesmo número de avaliações nos quesitos ruim, médio e bom, demonstrando o quão distinta é a opinião dos estudantes sobre esse tema. Com relação à refeição oferecida, foram citadas as dificuldades de adequação da escola ao comprometido do programa de fornecer um jantar aos estudantes. Inicialmente, por falta de envio da merenda, aos estudantes eram servidos biscoito e suco, o que ocasionou uma série de reivindicações, inclusive abaixoassinado dos alunos requerendo "a janta" como refeição. Após tal conquista, a maioria dos estudantes avalia de média a boa a refeição oferecida.

Importante destacar que nenhum estudante avaliou os professores e servidores como ruins e que a maioria absoluta acha que estes são bons profissionais. Com relação à bolsa de auxílio financeiro, a realidade é oposta, pois a grande maioria dos estudantes avaliou como ruim. Afinal, nenhum deles recebeu este auxílio financeiro que seria repassado diretamente do MEC para o estudante via cartão de débito enviado pelos correios à residência do estudante.

Quanto ao transporte oferecido, a maioria dos estudantes avaliou como médio e bom, cabendo destacar que os 
problemas iniciais no transporte, como as rotas extensas, o horário cedo (antes das 18 horas, o que dificultava para quem vinha do trabalho) e o impedimento de transportar crianças foram solucionados e levaram à avaliação boa deste serviço. Com relação à infraestrutura da escola, a maioria dos estudantes considera-a adequada, classificando-a como média e boa. Já com relação à limpeza da escola, cabe destacar a falta de um profissional da limpeza no noturno, que levou parte dos estudantes a apontar a limpeza como ruim na escola. Com relação ao acolhimento das crianças, a maioria dos jovens declarou ser bom, apesar das dificuldades da falta de espaço físico e dos materiais adequados conforme retratado por Figueiredo (2016).

\section{Considerações finais}

O Programa Projovem Campo atende a especificidade do campo, ao realizar o Tempo-escola alternado com o Tempocomunidade. Também cumpre a adequação pedagógica do conteúdo à realidade do campo. Esses dois quesitos foram apontados por professores e alunos como método de ensino positivo na execução do Projovem Campo.

Destacável as diversas ações previstas como transporte, alimentação, bolsa auxílio e o acolhimento das crianças para que os jovens do campo possam estudar, atendendo a demanda dos movimentos sociais para adequação dos conteúdos, das escolas e do suporte necessário para continuidade dos estudos destes jovens. Contudo, apesar das ações desenhadas na formulação da política vimos que a execução não ocorreu da forma prevista.

Assim, as dificuldades na execução do Programa Projovem Campo no CEF Pipiripau II mostram os desafios da implementação desta política nas diversas unidades da Federação. $\mathrm{O}$ não cumprimento do pagamento da bolsa auxílio por parte do MEC e a falta de espaço físico adequado para o acolhimento das crianças, além dos outros problemas apontados, contribuíram, de fato, para a evasão dos jovens do Programa.

Ademais, o trabalho coletivo dos professores qualificou o trabalho pedagógico e, mesmo com adversidades, os estudantes foram ensinados $\mathrm{e}$ incentivados a lutar por seus direitos. Os jovens atendidos nesta unidade de ensino estão cientes de que a educação é um direito e não apenas um sonho e que é dever do Estado proporcionar infraestrutura e suporte às pessoas que por diversos motivos foram excluídas das escolas. 


\section{Referências}

Bento, M. (2014). Notas sobre a expressão da branquitude nas instituições. In Bento, M. A. S. et al. (Orgs.). Identidade, branquitude e negritude: contribuições para a psicologia social no Brasil: novos ensaios relatos de experiência e de pesquisa. São Paulo: Casa do Psicólogo.

Carvalho, M., Barbosa, T., \& Soares, B. (2010). Implementação de política pública: uma abordagem teórica e crítica. In $X$ Colóquio Internacional sobre Gestión Universitaria en América del Sur. Mar del Plata, Argentina.

Figueiredo, M. (2016). O programa Projovem campo $e$ as salas de acolhimento: um estudo de caso desta ação afirmativa para a conclusão da educação fundamental de jovens mulheres negras/ (Monografia de Especialização) Universidade de Brasília, Brasília.

Ipea. (2014). Situação social da população negra por estado/Instituto de Pesquisa Econômica Aplicada; Secretaria de Políticas de Promoção da Igualdade Racial. - Brasília: IPEA.

Ministério da Educação. (2009). Projeto Base ProJovem Campo - Saberes da Terra. Programa nacional de educação de jovens agricultores (as) familiares integrada à qualificação social e profissional. Brasília: MEC.

(2013). Secretaria

de Educação Continuada, Alfabetização, Diversidade e Inclusão. Termo de Referência: Projeto Unesco: "Fortalecimento de Políticas Educacionais para a Juventude".

Portilho, E. (2006). Escola e realidade do campo: o caso do Centro de Ensino Pipiripau II, Planaltina/DF. (Dissertação de Mestrado). Universidade de Brasília, Brasília.

Recebido em: 21/03/2017

Aprovado em: 31/03/2017

Publicado em: 31/07/ 2017

Como citar este artigo / How to cite this article / Como citar este artículo:

APA:

Figueiredo, M. M. A., \& Freitas, M. C. S. (2017). Educação do Campo e o programa Projovem Campo em Planaltina/DF. Rev. Bras. Educ. Camp., 2(2), 502-519.

DOI:

http://dx.doi.org/10.20873/uft.2525-

4863.2017v2n2p502

ABNT:

FIGUEIREDO, M. M. A.; FREITAS, M. C. S. Educação do Campo e o programa Projovem Campo em Planaltina/DF. Rev. Bras. Educ. Camp., Tocantinópolis, v. 2, n. 2, p. 502-519, 2017. DOI: http://dx.doi.org/10.20873/uft.25254863.2017v2n2p502

\section{ORCID}

Marina Morenna Alves de Figueiredo

iD http://orcid.org/0000-0001-7050-9791

Maria da Conceição da Silva Freitas

http://orcid.org/0000-0002-6557-3171 